\title{
BIM aplicado ao projeto de fôrmas de madeira em estrutura de concreto armado
}

\author{
BIM applied to plywood formwork design in reinforced \\ concrete structures
}

\begin{abstract}
Romeu da Silva Neiva Neto
Regina Coeli Ruschel
Resumo

$\mathbf{O}$

Projeto Construtivo de Fôrmas de Madeira (PCFM) faz uso tradicionalmente de ferramentas CAD na representação bidimensional, limitando sua inserção no contexto de Building Information Modeling (BIM). Considerando que BIM se encontra em grande expansão no mercado nacional esta pesquisa visa apontar um caminho para se vencer esta limitação. Propõe-se uma biblioteca de componentes para o projeto de fôrmas de madeira, incluindo usos de BIM tais como a Modelagem, a Quantificação, a Simulação 4D e procedimentos associados. O método de pesquisa utilizado foi a Constructive Research. Os componentes para a biblioteca foram desenvolvidos na ferramenta BIM Revit Structure. A proposta foi validada: em ambiente de ensino, escritório de projeto e na prática. Verifica-se que a pesquisa é consonante com os poucos estudos internacionais pioneiros e semelhantes, sendo contextualizada para o cenário nacional. Observa-se também que todas as pesquisas que tratam de BIM associado a fôrmas requerem um modelo de informação que inclua a modelagem de fôrmas no mesmo. Desta forma, este estudo é também fundamental, pois amplia desdobramentos da incorporação de BIM na cadeia produtiva da construção civil.

Palavras-chave: Projeto de fôrmas de madeira. BIM. Projeto de estrutura de concreto armado.

Romeu da Silva Neiva Neto Innovar Construtora Goiânia - GO - Brasil

Regina Coeli Ruschel Universidade Estadual de Campinas Campinas - SP - Brasil

Recebido em 25/11/14 Aceito em 02/06/15

Abstract

The authoring of construction documents on plywood formwork for concrete structures traditionally makes use of CAD tools in a bi-dimensional representation, limiting its inclusion in Building Information Modeling (BIM). Considering that BIM is in great expansion in Brazil, this study proposes a solution to overcome this limitation. We propose a Formwork BIM component library including uses such as virtual prototyping (modeling), quantification, $4 D$ simulation and associated processes. The research method used was constructive research. The components for the library were based on the BIM tool Revit Structure. The proposal was validated in a learning environment, in a design office and in practice. We have found that the research study is in line with the few existing similar international pioneering studies, and it is contextualized in the Brazilian situation. The researchers also observed that that all research dealing with BIM associated with formwork requires an information model that includes the modeling of formworks. Thus, this study is also essential, since it enables and expands the developments of the incorporation of BIM into the production chain of the construction industry.

Keywords: Formwork design. BIM. Design of reinforced concrete structure. Model. Parametric.
\end{abstract}




\section{Introdução}

O Projeto Construtivo de Fôrma de Madeira (PCFM) é praticamente inexplorado quando se trata da incorporação de BIM no Brasil. O PCFM faz parte do Projeto dos Sistemas de Construção (Construction System Design), sendo o último um dos usos de BIM apresentados pelo roteiro de implantação de BIM sugerido pelo Computer Integrated Construction Research Program (2011).

Segundo o Computer Integrated Construction Research Program (2011), no Projeto dos Sistemas de Construção são requeridos usuários com as habilidades de manipulação, navegação, criação e revisão de um modelo. Outro fator importante é o conhecimento dos sistemas construtivos e práticas usuais de cada serviço desenvolvido em um canteiro de obra. Esse conhecimento é primordial para a tomada de decisão. Nesta etapa utiliza-se essas habilidades no intuito de melhorar o planejamento dos sistemas construtivos e aumentar a construtibilidade dele, gerando produtividade, segurança e a quebra de barreiras de comunicação (CHI; HAMPSON; BIGGS, 2012; JIANG; LEICHT, 2015; KANNAN; SANTHI, 2013; LEE; HAM; LEE, 2009). Portanto, investir esforços para a incorporação de BIM em Projeto dos Sistemas de Construção contribui para atender à demanda de otimização de processos para melhorar a produtividade e atuação dos profissionais do setor da construção (CÂMMARA...; FUNDAÇÃO..., 2012)

O PCFM é um processo da etapa de construção. A Figura 1 apresenta parte do esquema geral do plano de execução de BIM segundo o Computer Integrated Construction Research Program (2011), destacando possíveis usos de BIM associados ao PCFM. Estes usos são modelagem paramétrica para suporte a autoria de soluções, de quantificação e orçamentação para estimativa de custo; de compatibilização 3D para a coordenação de projeto; de prototipagem virtual para documentação e visualização do modelo; de simulação 4D para o planejamento da obra e de análises de múltiplos desempenhos. Estes usos podem ocorrer nas etapas de projeto de Detalhamento de Processo e Produto e de Planejamento definidas nos termos de Melhado (2005), que resultam nos produtos Projeto Executivo e Projeto para Produção.

Este trabalho tem como intuito propor um método para o desenvolvimento do PCFM a partir de um processo de projeto no contexto da modelagem da informação da construção. Essa inserção foi feita através da criação de uma biblioteca de componentes para o PCFM. A análise feita nesse artigo restringe-se à aplicação e validação do processo de projeto de fôrmas para edifícios de múltiplos pavimentos em concreto armado.

\section{Revisão bibliográfica}

O Projeto para Produção ganhou destaque no Brasil dentro dos canteiros de obra, através de iniciativas privadas de construtoras nas décadas de 1980 e 1990, como a iniciativa Encol-Epusp (BARROS; MELHADO, 2006; SILVA, 2003). Essas parcerias entre a iniciativa privada e a academia renderam para o mercado de construção civil nacional profissionais de projetos que até então inexistiam no mercado. Esses projetistas se especializaram em projetos tais como o Projeto Construtivo de Alvenaria de Vedação e o Projeto Construtivo de Fôrmas para Concreto Armado (SABBATINI; AGOPYAN, 1991).

Essa categoria de projetos já era conhecida na indústria metalúrgica e da construção civil americana como Shop Drawings, podendo ser caracterizada, segundo Pietroforte (1997) como a maior aproximação entre os produtos descritos nessa documentação e sua verdadeira construção. Boehmig (1990) salienta a importância dessa categoria de projetos, tendo em vista uma gestão de projetos que garanta ao máximo o nível de informação, tanto ao construtor quanto ao setor operacional que irá utilizar tal documentação no canteiro de obras

A racionalização do processo construtivo é outro intuito dessa categoria de projeto. Melhado e Fabrício (1998) defendiam que a fase de projeto é determinante no desenvolvimento de inovações em métodos construtivos, caracterizando-se como uma fase de planejamento e organização das informações sobre a técnica construtiva a ser adotada em um empreendimento.

Outros autores já destacaram as facilidades e vantagens de se utilizar a simulação 4D para a coordenação das etapas construtivas (GELISEN, 2014; BIOTTO; FORMOSO; ISATTO, 2015). Essas vantagens serão mais bem aproveitadas com a existência de modelos de informação de todos os sistemas envolvidos. 
Figura 1 - Mapa do processo relativo à documentação da construção

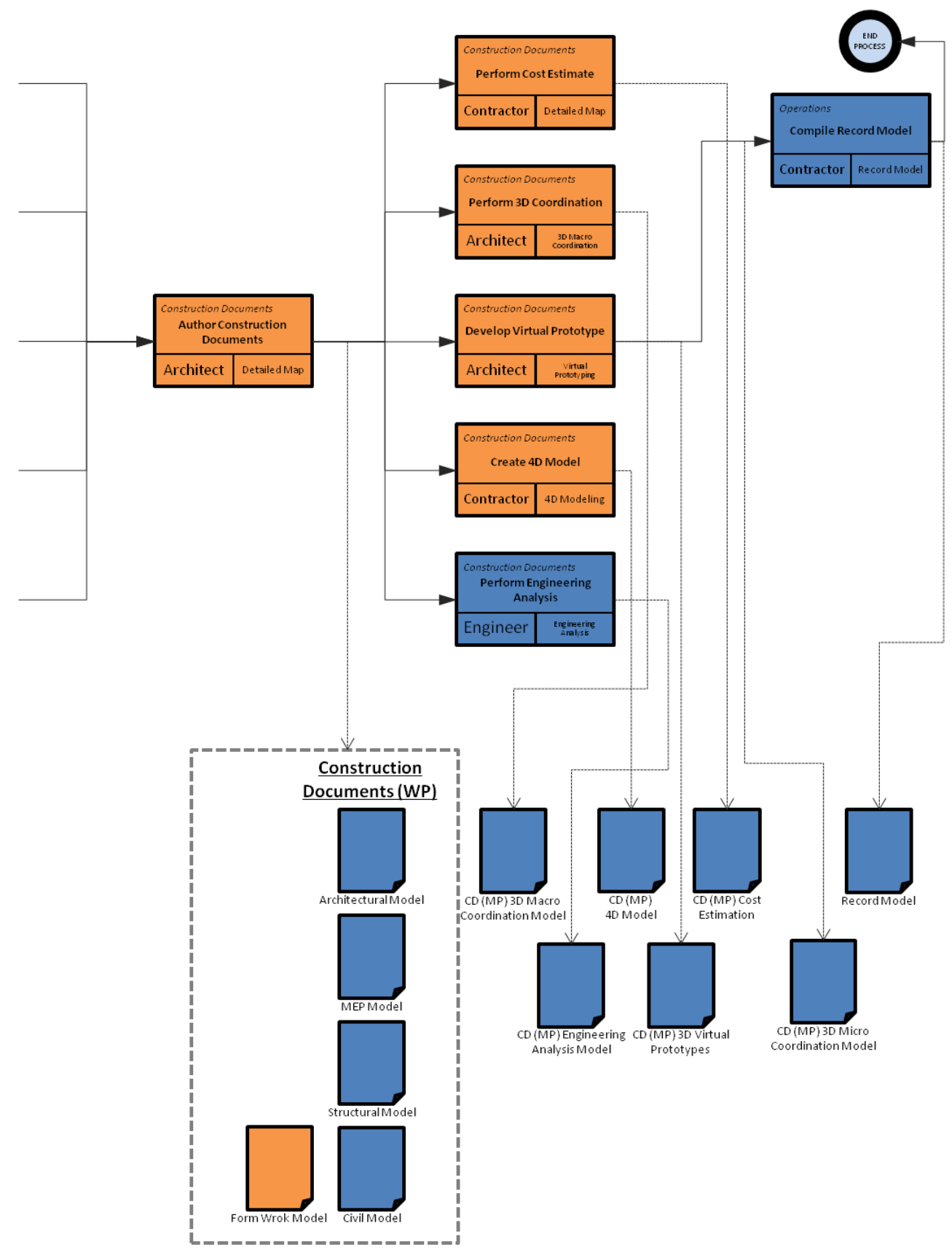

Fonte: adaptado de Computer Integrated Construction Research Program (2011).

\section{Trabalhos correlatos}

Para se validar o objetivo da pesquisa, a abordagem ao tema foi confrontada com pesquisas recentes correlatas (últimos 5 anos). Realizou-se busca nas bases referenciais - Sciencedirect, Web of Science, ProQuest e ASCE Library - utilizandose as palavras-chave BIM e Formwork no título, resumo ou assunto dos artigos, incluindo artigos em periódicos, proceedings e capítulo de livro. O resultado desse levantamento apontou 11 artigos listados e caracterizados no Quadro 1.
Identificaram-se dois focos de pesquisa tendo fôrmas como tema principal ou fôrmas como tema secundário. As pesquisas em BIM abordando fôrmas como tema principal propõem $\mathrm{O}$ desenvolvimento de componentes e processos associados, tratam da verificação da construtibilidade desta estrutura temporária ou abordam seu rastreamento automático. As pesquisas em BIM incluindo fôrmas como tema secundário tratam do controle do posicionamento de estruturas de concreto na concretagem, do posicionamento otimizado de guindastes para a 
movimentação de estruturas temporárias e da automação na geração de desenhos de produção. Conclui-se que a inclusão do paradigma BIM no estudo de fôrmas é recente e ainda incipiente, pois se encontrou um número limitado de estudos, muitos ainda publicados em eventos científicos ou com fôrmas como foco secundário no estudo.

Das pesquisas em BIM encontradas com foco principal em fôrmas, duas têm enfoque semelhante a este estudo, ou seja, o desenvolvimento de componentes e processo associados (IRIZARRY; AKNOUKH; MEADATI, 2011; CHI; HAMPSON; BIGGS, 2012).

Irizarry, Aknoukh e Meadati (2011) desenvolvem, para o contexto de ensino, um repositório de componentes para o desenvolvimento de modelos BIM de fôrmas de concreto armado. Foram desenvolvidas famílias de componentes de fôrmas no Revit Structure e processos para: estudos de carga, estudos de alternativas de projeto, extração de quantitativos, extração de desenhos de produção e análises de construtibilidade. A análise da construtibilidade se dá pela observação de simulações 4D do processo de montagem e desmontagem das fôrmas e também a partir de desenhos de produção mais bem elaborados com visualizações em 3D.

Chi, Hampson e Biggs (2012) apresentam as metas de um projeto de pesquisa a ser desenvolvido em parceria entre governo e indústria em Queensland, na Austrália, com o objetivo de desenvolver componentes BIM para componentes temporários da construção, como andaimes e fôrmas. A ênfase do projeto é a melhoria da produtividade em projeto e construção e a incorporação de parâmetros de segurança.

Ainda, nos estudos de BIM com foco principal em fôrmas encontram-se: Kannan e Santhi (2013), Jiang e Leicht (2015) e Jiang, Leicht e Kremer (2014), que tratam da questão da verificação da construtibilidade, e Turkan et al. (2013), que abordam o rastreamento automático de estruturas temporárias.

\section{Quadro 1 - Levantamento em bases referenciais com as palavras-chave BIM \& Formwork}

\begin{tabular}{|c|c|c|c|c|c|c|}
\hline REFERÊNCIA & 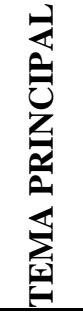 & 量 & 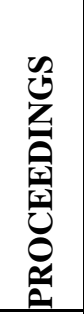 & 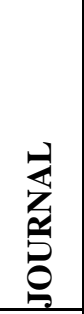 & 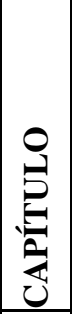 & ÊNFASE DA PESQUISA \\
\hline Irizarry, Aknoukh e Meadati (2011) & $\mathrm{X}$ & & $\mathrm{X}$ & & & $\begin{array}{l}\text { Repositório de componentes BIM } \\
\text { de fôrmas }\end{array}$ \\
\hline Chi, Hampson e Biggs (2012) & $\mathrm{X}$ & & $\mathrm{X}$ & & & $\begin{array}{l}\text { Desenvolvimento de componentes } \\
\text { BIM para fôrmas }\end{array}$ \\
\hline Turkan et al. (2013) & $\mathrm{X}$ & & $\mathrm{X}$ & & & $\begin{array}{l}\text { Rastreamento automático de } \\
\text { estruturas temporárias incluindo } \\
\text { fôrmas }\end{array}$ \\
\hline Jiang e Leicht (2014) & $\mathrm{X}$ & & & $\mathrm{X}$ & & Verificação da construtibilidade \\
\hline Jiang, Leicht e Kremer (2014) & $\mathrm{X}$ & & $\mathrm{X}$ & & & Verificação da construtibilidade \\
\hline Kannan e Santhi (2013) & $\mathrm{X}$ & & & $\mathrm{X}$ & & Verificação da construtibilidade \\
\hline $\begin{array}{l}\text { Golparvar-Fard, Savarese e Peña- } \\
\text { Mora (2010) }\end{array}$ & & $\mathrm{X}$ & $\mathrm{X}$ & & & $\begin{array}{l}\text { Rastreamento automático do as- } \\
\text { built }\end{array}$ \\
\hline $\begin{array}{l}\text { Alwisy, Al-Hussein e Al-Jibouri } \\
(2012)\end{array}$ & & $\mathrm{X}$ & $\mathrm{X}$ & & & $\begin{array}{l}\text { Molduras de madeira (wood- } \\
\text { framing) }\end{array}$ \\
\hline Kang, Ganapathi e Faghihi (2012) & & $\mathrm{X}$ & & & $\mathrm{X}$ & $\begin{array}{l}\text { Qualidade do posicionamento de } \\
\text { estruturas na obra }\end{array}$ \\
\hline Luth, Schorer e Turkan (2014) & & $\mathrm{X}$ & & $\mathrm{X}$ & & $\begin{array}{l}\text { Desenhos de produção a partir de } \\
\text { modelos BIM }\end{array}$ \\
\hline Wang et al. (2015) & & $\mathrm{X}$ & $\mathrm{X}$ & & & $\begin{array}{l}\text { Transporte de estruturas } \\
\text { temporárias }\end{array}$ \\
\hline & $55 \%$ & $45 \%$ & $64 \%$ & $27 \%$ & $9 \%$ & \\
\hline
\end{tabular}

186 Neiva Neto, R. da S.; Ruschel, R. C. 
Jiang e Leicht (2015) apresentam um sistema de verificação da construtibilidade de estruturas, que inclui a avaliação das fôrmas, por meio de um conjunto de regras no software de checagem de modelos Solibri. A avaliação é realizada sobre um modelo BIM da edificação que inclui a estrutura e fôrmas. O conjunto de regras foi baseado no conhecimento levantado por estudo com especialistas (JIANG; LEICHT; KREMER, 2014).

Kannan e Santhi (2013) apresentam um levantamento em obras de edifícios altos na Índia com o enfoque na comparação de sistemas de fôrmas: tradicional, deslizante e trepante. Além do estudo comparativo, os autores demonstram como substituir sistemas tradicionais de fôrmas por sistemas de fôrmas trepantes em modelos BIM estruturais, apresentando uma proposta simplificada de modelagem geométrica destes sistemas. A modelagem em BIM do sistema de fôrmas dá suporte a avaliações de construtibilidade; entretanto, os autores não especificam como.

Turkan et al. (2013) avaliam a viabilidade de incorporar às soluções de controle automático da construção por rastreamento da estrutura componentes temporários como as fôrmas. Comparam-se dois métodos de escaneamento e reconhecimento das fôrmas para estrutura de concreto identificando seu potencial para comparação com o modelo BIM. Ainda se observa dificuldade no reconhecimento de escoramentos.

Outras pesquisas abordam o tema de BIM associado a fôrmas, mas de forma secundária, como Kang, Ganapathi e Faghihi (2012), Wang et al. (2014), Alwisy, Al-Hussein e Al-Jibouri (2012) e Luth, Schorer e Turkan (2014). Kang, Ganapathi e Faghihi (2012) tratam do controle do posicionamento de fôrmas de concreto com estações totais baseado em informações do modelo BIM para garantir qualidade de posicionamento de estruturas de concreto na concretagem. Wang et al. (2014) utilizam modelos BIM e simulações 4D para estudar posicionamentos otimizados de guindastes para a movimentação de estruturas temporárias. Finalmente, Alwisy, Al-Hussein e AlJibouri (2012) apresentam uma proposta para a construção modular manufaturada de estruturas de madeira permitindo a automação na geração de desenhos de produção. Similarmente, Luth, Schorer e Turkan (2014) abordam a automação de desenhos de produção por meio de modelos de informação de alta definição.

Outro trabalho no mesmo campo que merece ser destacado é o de Williams et al. (2011), que aborda os termos de construtibilidade dos elementos da fôrma através da parametrização e a fabricação digital dos componentes para fôrmas complexas. Todo o estudo aborda o processo de projeto que envolve o desenvolvimento de sistemas de fôrmas adequados ao processo criativo do arquiteto em fôrmas complexas de concreto. No entanto, o processo descrito envolve ferramentas $\mathrm{CAD}$ de projeto e suas extensões não envolvem BIM como auxílio ao processo.

Verifica-se, a partir dessa análise com estudos correlatos, que esta pesquisa é pioneira, pois é consonante com os poucos estudos semelhantes internacionais e contextualizada para o cenário nacional. Observa-se também que todas as pesquisas que tratam de BIM associado a fôrmas, mesmo com foco secundário, requerem um modelo de informação que inclua a modelagem de fôrmas nele. Dessa forma, este estudo além de pioneiro é fundamental, pois viabiliza desdobramentos e ajuda a ampliar a incorporação de BIM na cadeia produtiva da construção civil.

\section{Método constructive research aplicado}

A pesquisa como um todo segue a metodologia da pesquisa construtiva (constructive research) (LUKKA, 2003). Essa metodologia foi adotada porque se entende que o objetivo geral da pesquisa é criar um artefato composto de objeto e processo para sua utilização. Nesta pesquisa o objeto é de uma biblioteca de componentes de fôrmas de madeira para concreto armado e o processo correspondente de projeto de fôrmas de madeira modificado. Vislumbra-se modificação no processo pela otimização através de etapas automatizadas (documentação, quantificação) e pela ampliação com a incorporação da simulação $4 \mathrm{D}$ ao processo.

Lukka (2003) delineia a pesquisa construtiva em 7 etapas:

(a) etapa 1: identificar um problema prático relevante;

(b) etapa 2: examinar o potencial de pesquisa em conjunto com o setor-alvo;

(c) etapa 3: obter conhecimento teórico e prático da área;

(d) etapa 4: propor uma solução inovadora e desenvolver uma construção que solucione o problema identificado;

(e) etapa 5: implementar e testar a solução;

(f) etapa 6: avaliar aplicabilidade da solução; e

(g) etapa 7: identificar e analisar as contribuições teóricas. 
Este artigo apresenta uma síntese das etapas 4 a 7 desenvolvidas.

O guia de implementação de BIM (COMPUTER..., 2011) indica que toda etapa de autoria (momento de criação ou aprimoramento de uma solução) do processo de projeto é seguido por etapas de:

(a) estimativa de custo, coordenação 3D (compatibilização);

(b) desenvolvimento de protótipos virtuais; e

(c) simulação 4D e análise de desempenho (Figura 1).

Dessa forma, adotaram-se ciclos de desenvolvimento incorporando as etapas em que o projeto de fôrmas hoje já inclui (estimativa de custo) e pode incorporar com BIM (desenvolvimento do protótipo virtual e simulação 4D). Estes ciclos foram incluídos nas etapas - da formulação da solução (etapa 5) e da implementação e teste da solução (etapa 6) - do delineamento da pesquisa construtiva para PCFM. Cada ciclo se diferencia pela ênfase: no desenvolvimento de protótipos virtuais (denominada modelagem), na estimativa de custo e na simulação 4D. A Figura 2 detalha a sequência de atividades desenvolvidas em cada ciclo e a ocorrência de interações entre ciclos e intraciclos.

$\mathrm{Na}$ etapa de avaliar aplicabilidade da solução, do delineamento da Pesquisa Construtiva, realizaramse experiências específicas como avaliar a receptividade da proposta por escritório de projetos do mercado; aplicar a modelagem das fôrmas em BIM e processos associados num ambiente didático e aplicar na prática desenvolvendo um projeto de fôrmas para um empreendimento comercial.

$\mathrm{Na}$ etapa de identificação e análise das contribuições teóricas buscou-se refletir sobre a contribuição atingida em comparação a estudos recentes similares.

\section{Implementação da solução}

O Revit, assim como toda ferramenta de modelagem BIM, gera e manipula modelos de construção. Os modelos de construção são compostos por componentes de construção,

[...] representados com representações digitais inteligentes (objetos) [...] que podem ser associados com atributos (gráficos e de dados) computáveis e regras paramétricas [...] (EASTMAN et al., 2014, p. 13).
A definição destes objetos é realizada no Revit em famílias. Uma família é definida como “[...] um grupo de elementos com um conjunto de propriedades comum, chamado de parâmetros, e uma representação gráfica relacionada" (AUTODESK, 2015).

Existem três classes de famílias no Revit: Famílias de Sistema, Famílias Carregáveis, e Famílias Locais. As Famílias de Sistema definem os componentes básicos para a montagem de um Modelo de Construção (paredes, telhados, pisos, dutos e tubulação, entre outros) e componentes de configuração do ambiente de projeto (níveis, eixos e folhas de desenho). As Famílias de Sistema são predefinidas no Revit e não podem ser modificadas ou expandidas. As Famílias Carregáveis são famílias utilizadas para criar componentes de construção além dos básicos, tais como portas e janelas, e também equipamentos e elementos de anotação. As Famílias Carregáveis são criadas em arquivos externos e importados para o ambiente do Revit para sua utilização. As Famílias Locais são utilizadas para criar componentes específicos dentro de cada projeto na medida do necessário.

Todas as famílias do Revit são gerenciadas em uma estrutura hierárquica que se inicia com a Categoria da Família; em seguida tem-se o Tipo de Família e por fim a Instância da Família. A Categoria da Família representa uma classificação geral para cada parte do modelo. Essas Categorias podem ser, por exemplo, de Parede, Porta, Mobiliário, Janela, Pilares Estruturais, Fundações, Conduítes Elétricos, Tubos, Conexões Hidráulicas, Vegetação, entre outras. Já o conjunto de elementos de uma família com diferentes valores de parâmetros porém com um mesmo nome e significado denomina-se Tipo de Família. As Instâncias da Família são as diferentes variações do Tipo de Família que são criadas dentro do projeto. As Instâncias da Família podem ser inseridas múltiplas vezes no projeto criando os objetos que compõem o modelo.

A criação das famílias de fôrmas requer um recurso das famílias do Revit conhecida como famílias aninhadas ou nested families. Assim como o próprio nome sugere, permite inserir famílias dentro de outras famílias (Figura 3). Para as famílias de fôrmas, foram criados primeiramente seus componentes básicos, que irão compor cada subsistema do sistema de fôrmas. Esses componentes básicos são componentes geralmente de madeira tais como o sarrafo, o pontalete, o painel de chapa compensada, entre outros, pois são esses os elementos que compõem as fôrmas de pilar, fôrmas de viga e fôrmas de laje. 
Depois de feitos os aninhamentos, segue-se o processo de estruturação da família. Essa estruturação requer planejamento, relacionado à escolha do template a ser utilizado para a criação da família. Também é necessário o uso de funções booleanas e condicionais para estabelecer relações entre os parâmetros, planos de referência, sólidos e o comportamento geral da família no modelo de informação da construção.

Esse processo repetiu-se para os componentes das fôrmas de pilar, vigas e lajes da estrutura de concreto de um edifício seguindo os passos descritos a seguir.

\section{Montagem da geometria dos componentes básicos}

Primeiramente procurou-se compreender a geometria dos componentes básicos das fôrmas, como o sarrafo, o pontalete, a placa de compensado, etc. Adotou-se a forma de um paralelepípedo descrita pelas dimensões de altura (h), largura (l) e profundidade (p). Porém, cada componente tem sua geometria dependente da maneira como ele é disposto na família de fôrmas que irá compor. Isso determina sua nomenclatura, como: sarrafo com largura e comprimento no plano dos eixos $\mathrm{x}$ e $\mathrm{y}$ respectivamente será denominado de sarrafo deitado. Cada uma das dimensões (altura, largura e profundidade) foi definida como parâmetros de acordo com a necessidade de cada componente (Figura 4).

Figura 2 - Ciclos integrados do delineamento da pesquisa construtiva: proposta de solução, implementação e teste

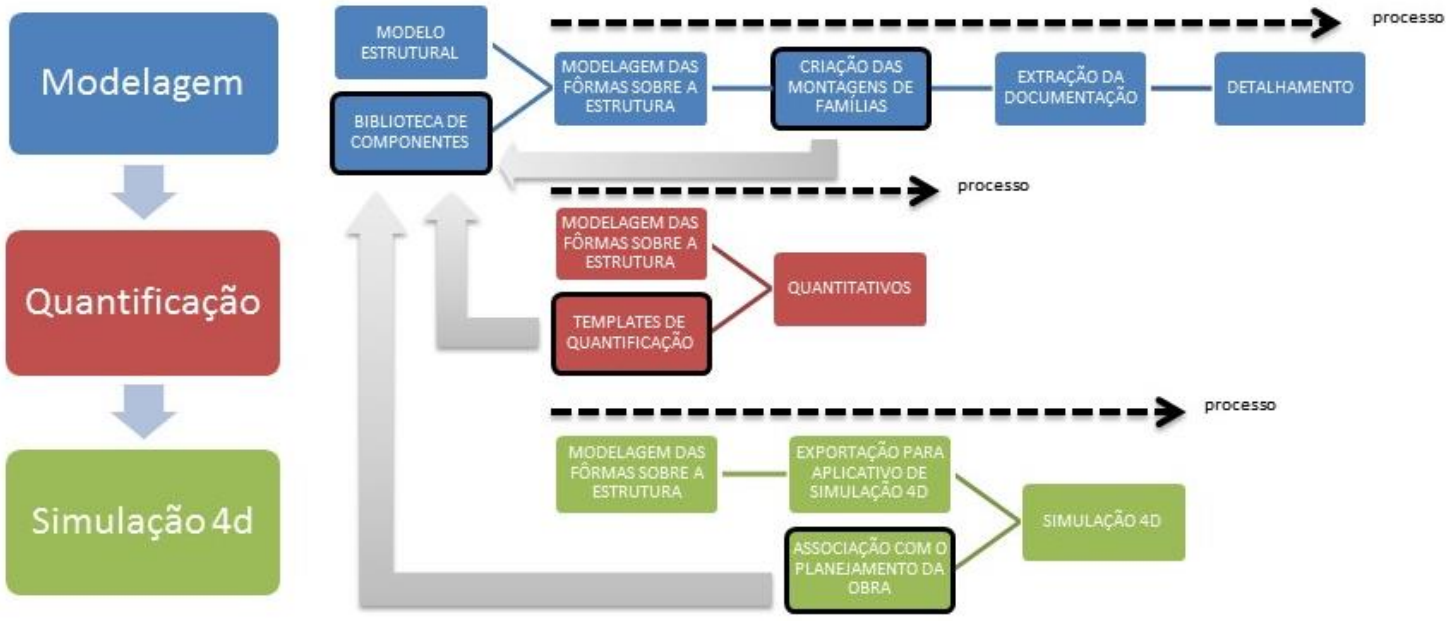

Figura 3 - Famílias aninhadas dos componentes de fôrma de madeira

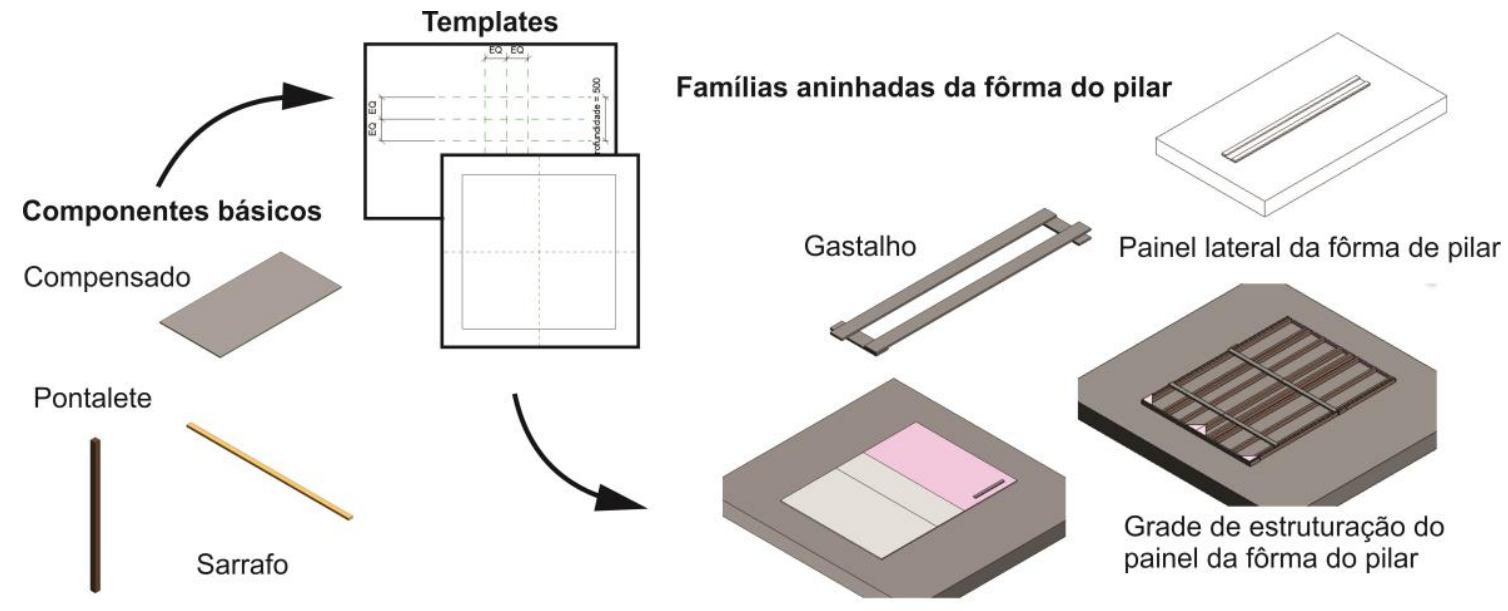

Fonte: Neiva Neto (2014).

Painel frontal da fôrma de pilar 
Figura 4 - Criação da geometria dos componentes básicos

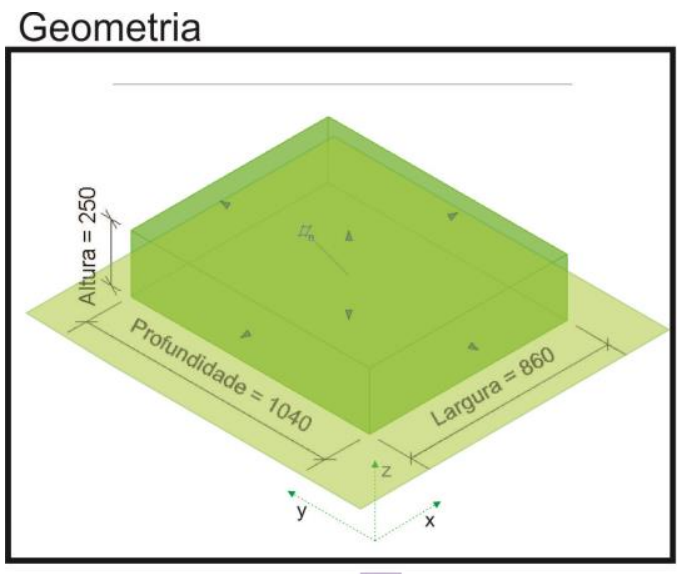

\section{Componentes básicos}

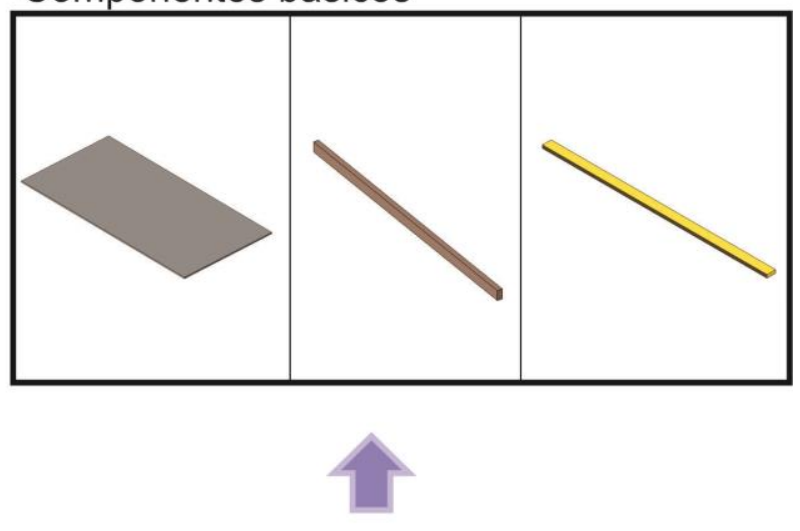

Parâmetros

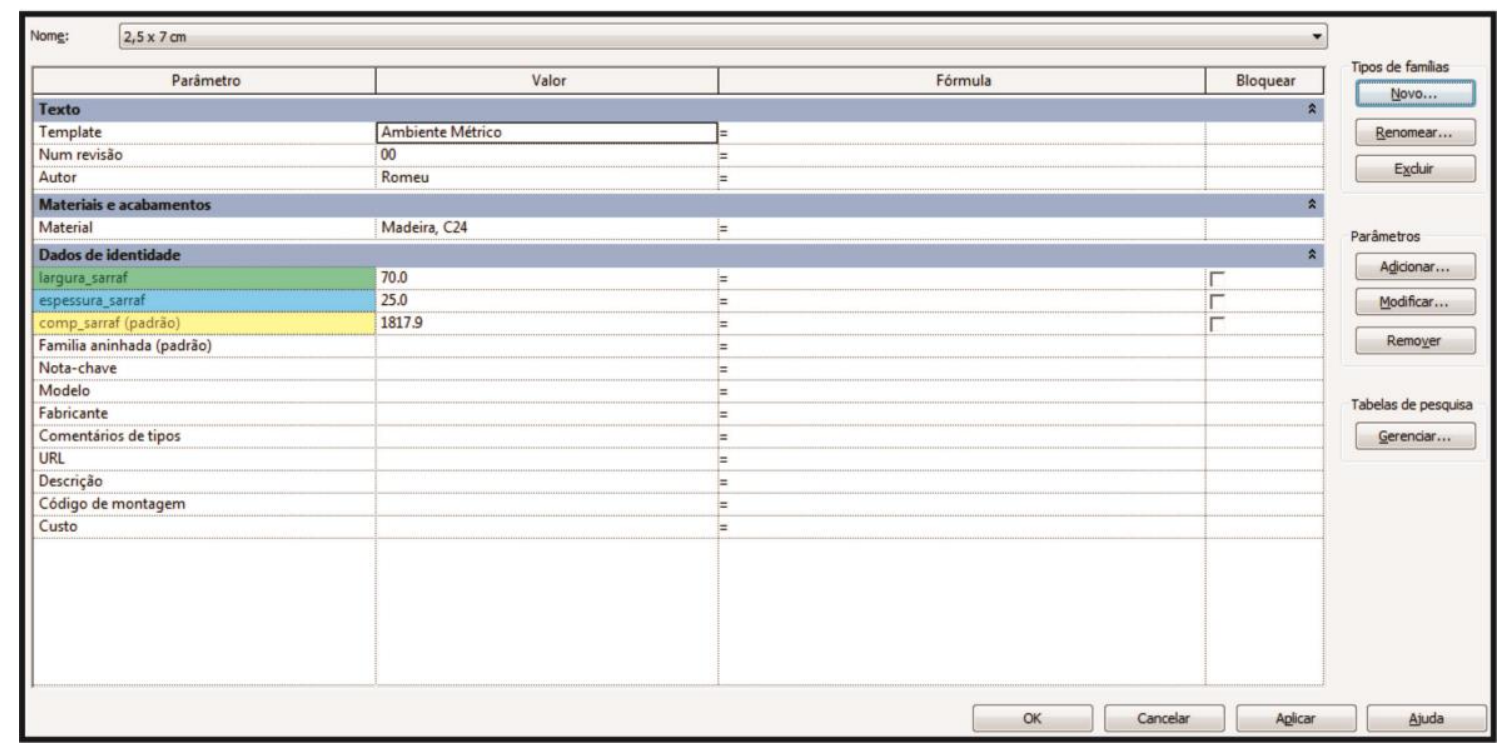

Fonte: Neiva Neto (2014).

Foi também necessário identificar a forma de modelagem a ser utilizada. $\mathrm{O}$ ambiente de famílias do Revit proporciona diversas formas de modelagem geométrica (como extrusão, mescla, revolução, varredura, mescla por varredura e vazios), desenvolvendo-se assim os parâmetros geométricos da família.

\section{Criação e classificação de parâmetros}

No ambiente de parametrização de famílias do Revit tem-se acesso aos parâmetros de uma família através da Tabela mostrada na Figura 4. Utilizando-se esse recurso foi possível criar novos parâmetros, classificá-los de acordo com o tipo de parâmetro (linear, texto, número inteiro, sim/não, material, etc.), agrupá-los de acordo com seu uso (dados, construção, dados de identidade, visibilidade, outros) e classificá-los de acordo com a natureza da disciplina na qual ele será utilizado (comum, estrutural, Avac...). Também foi possível criar fórmulas para a manipulação dos dados contidos nos parâmetros. Dessa forma, esses parâmetros determinaram as informações geométricas ou não geométricas da família.

\section{Determinação dos parâmetros de tipo, de instância e de compartilhamento}

A definição de um parâmetro de tipo de família ou parâmetro de instância de família, ou até de tipo ou instância compartilhados, é feita no momento da criação de um novo parâmetro na tabela de tipos de família. Essa nomenclatura é do ambiente de famílias e só existe para determinar o comportamento da família dentro do ambiente de projetos. 
Parâmetros de família são particulares de cada família e suas informações são acessíveis e manipuláveis apenas na seleção das famílias no ambiente do modelo. Já parâmetros compartilhados são acessíveis por tabelas do modelo e também por ferramentas de gerenciamento do modelo, tais como o Navisworks, da Autodesk. Por isso, foi necessário efetuar recursivos testes de implementação das famílias em um ambiente de projeto, para assim poder determinar quais as necessidades que cada família tinha para cada objetivo, considerando demandas de quantificação e da simulação 4D. Isso resultou na revisão do ciclo de modelagem a cada novo ciclo de desenvolvimento, ou seja, no ciclo de quantificação e de simulação 4D (Figura 3).

As famílias de componentes básicos possuem variações simples. Estas, em sua grande maioria, foram modeladas como extrusões ou varreduras, contendo quando necessário um vazio para definir um corte (isto é, corte no painel de compensado e corte no pontalete), e cada componente possuía uma característica específica para o uso.

Todos os componentes criados são ilustrados na Figura 5.

\section{Figura 5 - Componentes das fôrmas}
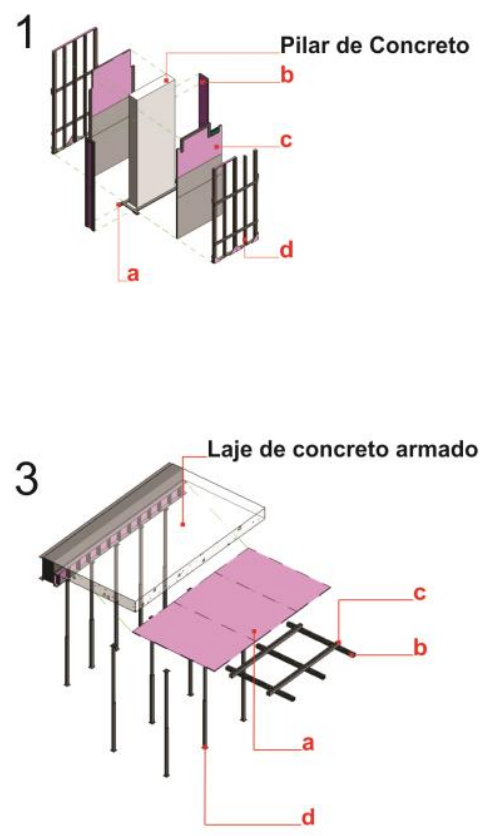

Fonte: adaptado de Neiva Neto (2014).

\section{Determinação de montagens para suporte ao processo de documentação}

Uma vez modeladas todas as fôrmas em um projeto (Figura 6) requer-se determinar para cada conjunto de famílias uma montagem ou assembly do Revit. Essa montagem cria uma classificação específica (Figura 7) para o conjunto de elementos selecionados do modelo e proporciona a criação de vistas de cada montagem individualmente. Esta funcionalidade do Revit é essencial para o processo de documentação do modelo, principalmente do modelo do PCFM, que consiste de várias famílias aninhadas, montadas de acordo com a necessidade da estrutura de concreto armado a ser moldada no local. Cada montagem foi criada separadamente para cada elemento de cada subsistema de fôrmas e enumerado de acordo com o elemento estrutural correspondente (ex.: fôrmas de pilar: montagem do Gastalho - P1, montagem do Painel frontal - P1, montagem do painel lateral - P1, etc.). Depois, criadas as montagens, são extraídas de cada uma vistas detalhadas dele, de acordo com a necessidade de representação gráfica do elemento para o processo de documentação (Figura 8). Essas vistas são utilizadas para compor um formato padrão de prancha, definindo um esquema de montagem com cotas e anotações que formarão a documentação a ser enviada para a confecção das fôrmas na obra.
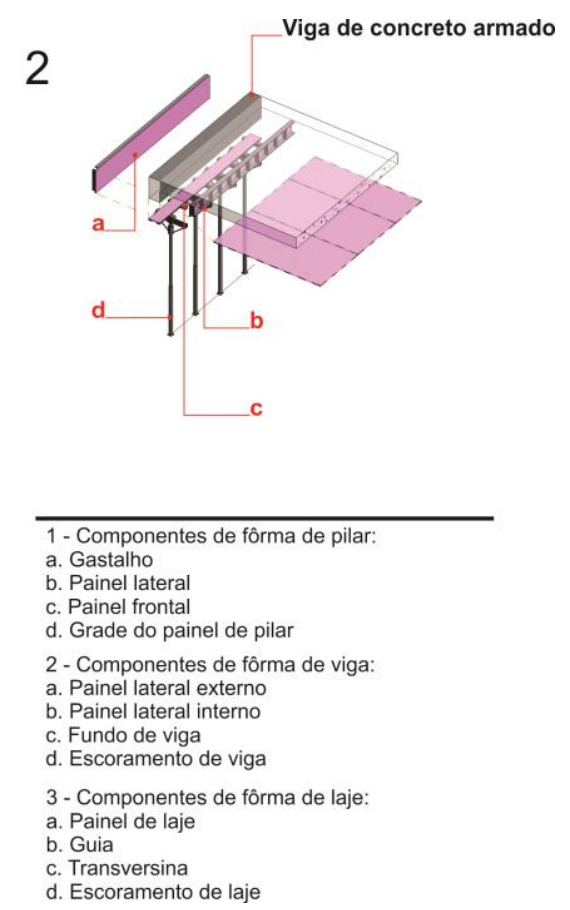
Figura 6 - Modelo estrutural com fôrmas instanciadas em pavimento tipo

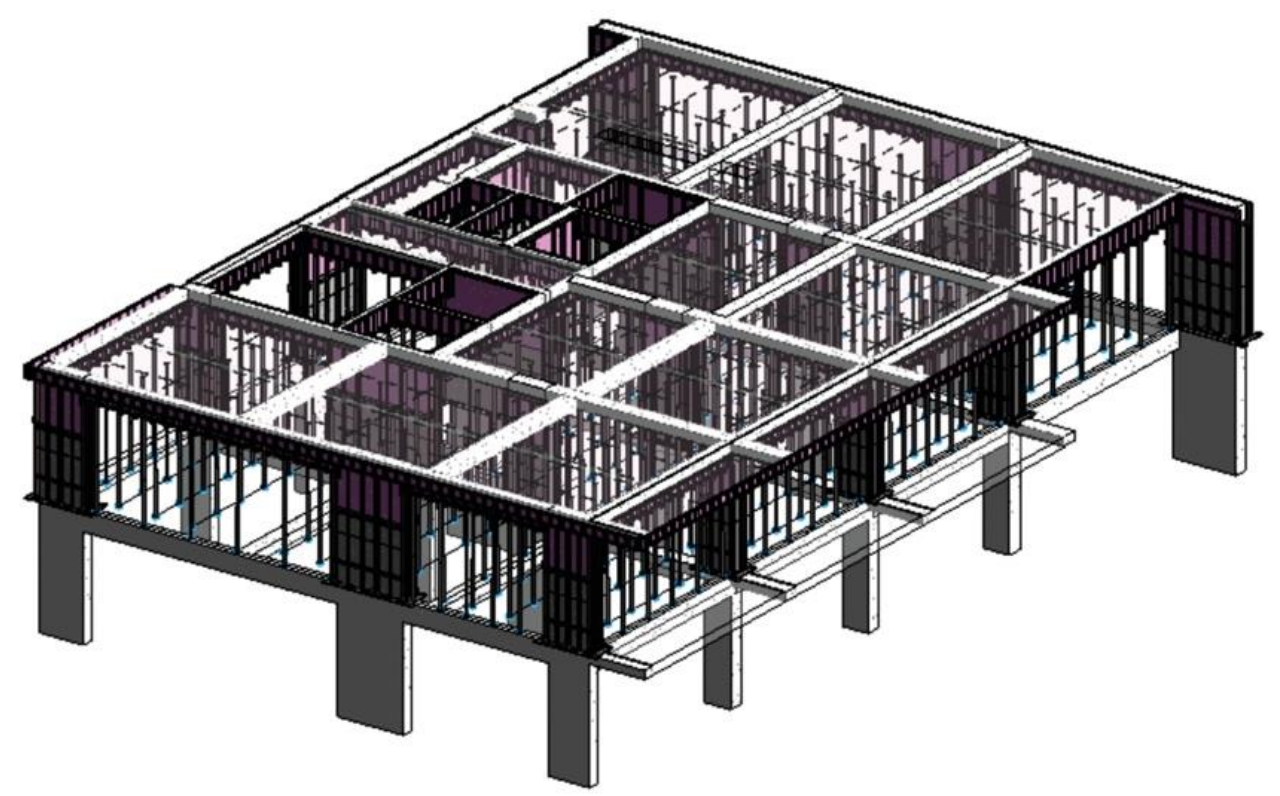

Fonte: Neiva Neto (2014).

Figura 7 - (a) Classificação específica para montagem ou assembly e (b) documentação através de montagens ou assemblies

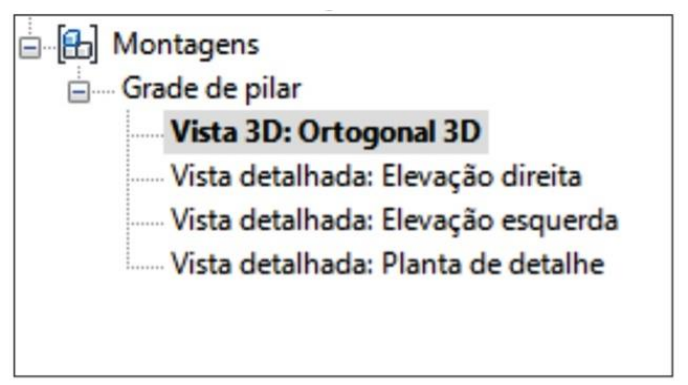

(a)

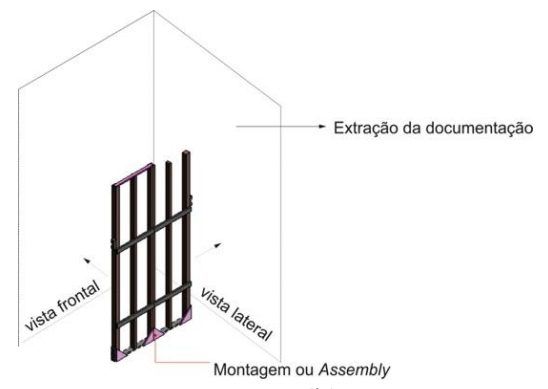

(b)

Fonte: Neiva Neto (2014).

Figura 8 - Documentação extraída da modelagem
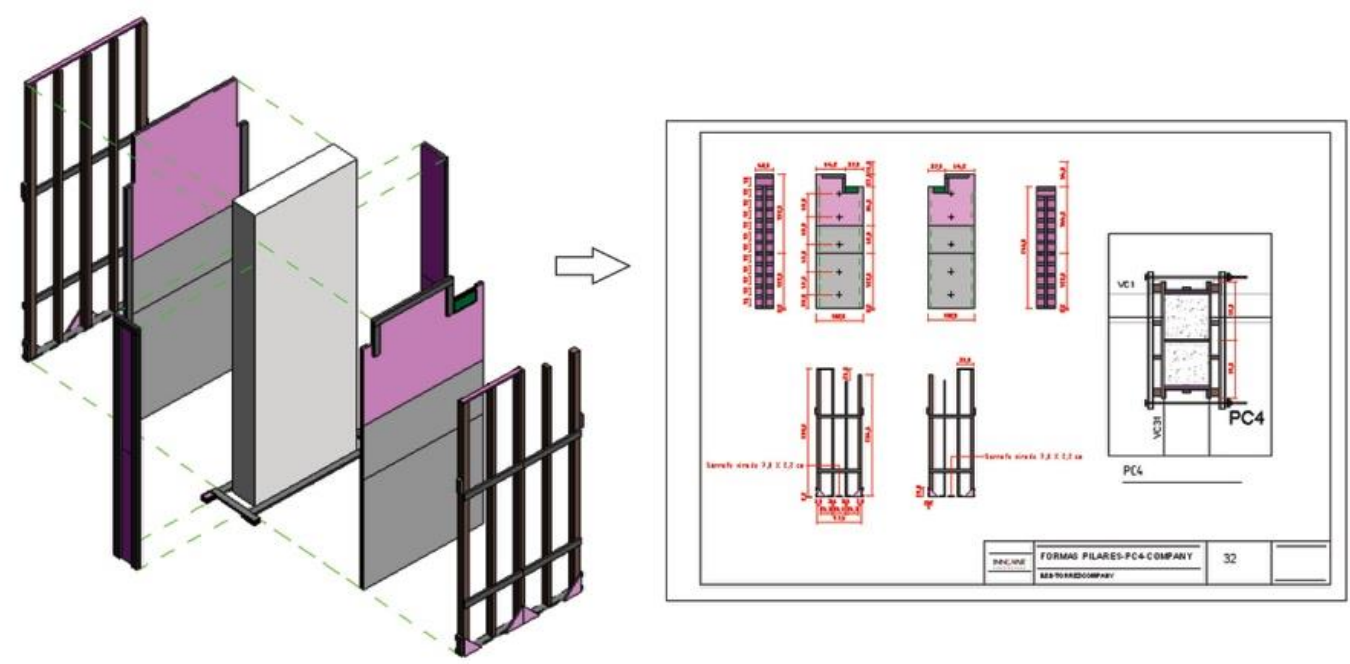

Fonte: Neiva Neto (2014).

192 Neiva Neto, R. da S.; Ruschel, R. C. 


\section{Suporte à quantificação}

A quantificação no Revit acontece através da criação de Tabelas. Essas tabelas são categorizadas em:

(d) tabelas de quantitativos;

(e) quantitativo de material;

(f) lista de pranchas; e

(g) lista de vistas.

As tabelas de quantitativos dos componentes se diferenciam no tipo de informação que será extraída, como o volume, a área superficial, o número de unidades que se repetem do mesmo objeto, entre outras informações. Nas tabelas de quantitativos, as informações são gerais para todos os componentes do projeto.

Para que seja possível a quantificação com as famílias de fôrmas, deve-se seguir uma estratégia simples, porém essencial quando se trata de trabalhar com famílias aninhadas no Revit. Para o processo de quantificação é importante entender como se comportam os parâmetros compartilhados, além de se entender o comportamento de cada parâmetro dos componentes básicos dentro das famílias aninhadas e qual seria a definição dos parâmetros das próprias famílias aninhadas, ou seja, se esses parâmetros seriam parâmetros de instância ou parâmetros de tipo.

$\mathrm{Na}$ solução desenvolvida, os parâmetros dos componentes básicos foram, em sua grande maioria, parâmetros que determinam as dimensões geométricas do componente (largura, espessura, comprimento, etc.). Porém, foi necessária a criação de outros parâmetros que determinassem funções complementares à família de componente básico. Um desses parâmetros foi o parâmetro para indicar a origem e o destino do componente básico na família aninhada, nomeado de ID de componentes. Ou seja, todas as famílias de fôrmas receberam um parâmetro ID para armazenar a informação "de onde vem" e "para onde vai" cada componente do sistema de fôrmas. Por exemplo, será possível separar a quantidade de sarrafos utilizados na confecção de cada painel de pilar. Esses parâmetros criados nas famílias de componentes básicos, tanto os geométricos quanto os não geométricos serão vinculados com informações de parâmetros da família aninhada. Durante a criação desses parâmetros descritos, vê-se necessária a determinação de que alguns deles sejam parâmetros compartilhados, pois assim todas as informações das famílias de fôrmas serão acessadas e manipuladas por tabelas de quantitativo do Revit.
As tabelas de quantitativos são associadas aos três subsistemas de fôrmas: de pilar, viga e laje. Para cada um destes subsistemas quantificaram-se os fixadores estruturais, quadro estrutural e conexões estruturais (Figura 9). Fixadores estruturais contêm as famílias de compensado. Dessa forma, foi possível a separação dos compensados do painel da fôrma de pilar, do compensado utilizado na fôrma de laje, por exemplo. O quadro estrutural contém todos os sarrafos e pontaletes das fôrmas. Dessa forma, foi possível a separação dos sarrafos utilizados na confecção das fôrmas de pilar daqueles sarrafos utilizados na confecção das fôrmas de viga. Conexões estruturais contêm as pequenas peças de sarrafo necessárias para a montagem das fôrmas.

\section{Avaliação de outras ferramentas BIM}

Existem outras ferramentas BIM para modelagem estrutural $^{1}$ que também poderiam ser utilizadas para o desenvolvimento da biblioteca de fôrmas em questão. Uma dessas ferramentas é o Tekla Structures, do Grupo Trimble. A implementação da solução aqui proposta na ferramenta Tekla seguiria uma abordagem semelhante à adotada na ferramenta Revit: criação de componentes básicos e criação de componentes compostos (aninhados) com comportamentos específicos, ambos desenvolvidos como componentes personalizados. $\mathrm{O}$ recurso de componentes personalizados no Tekla equivale ao de famílias carregáveis no Revit. Essa avaliação entre as plataformas Revit e Tekla indica que o desenvolvimento de bibliotecas de componentes atrelado às ferramentas em questão permite o reúso da estratégia de implementação, mas dependeria de recursos de interoperabilidade para o reúso dos componentes desenvolvidos. Da mesma forma, faz-se necessário avaliar de que forma os recursos de quantificação e de simulação 4D influenciam no desenvolvimento dos componentes.

\section{Validação da solução}

Com o intuito de avaliar a receptividade da proposta por um escritório de projetos do mercado, findado o primeiro ciclo de desenvolvimento (formulação de uma solução, implementação e teste), a solução para adoção de BIM para o Projeto Construtivo de Fôrmas de Madeira foi apresentada para um importante escritório de projetos especializado nessa área em São Paulo. Os projetistas demonstraram grande receptividade à solução, mesmo esta ainda não tendo a

\footnotetext{
${ }^{1}$ Disponível em:

<http://www.aecbytes.com/vendorhub/categories/BIMforStruct ure.html>.
} 
produtividade e o nível de automação da solução de projeto em CAD do escritório. Os projetistas confirmaram interesse na proposta por dois motivos: desejavam adotar o paradigma de BIM em seu processo de projeto, mas não conseguiam encontrar a forma de fazê-lo, e se interessavam em incorporar ao planejamento da obra o sistema de fôrmas através de estudos de simulação 4D. Entretanto, por restrições estratégicas comerciais do escritório, a colaboração em desenvolvimento conjunto não se viabilizou. Esse contato proporcionou o enriquecimento das informações contidas nas famílias de componentes, viabilizando a aplicação prática da biblioteca aos paradigmas de BIM. A primeira versão da proposta de modelagem em BIM do Projeto Construtivo de
Fôrmas de Madeira foi disponibilizada para o escritório. Essa iniciativa demonstrou o potencial de receptividade do mercado à pesquisa em questão.

Outra atividade de validação da solução foi realizada, no segundo semestre de 2013, em uma disciplina do curso de graduação de Engenharia Civil da Faculdade de Engenharia Civil, Arquitetura e Urbanismo (FEC) da Unicamp. O exercício requeria a instanciação das fôrmas (Figuras 10, 11 e 12) em dois pavimentos tipo de uma estrutura de concreto armado, a elaboração de um cronograma de concretagem do pavimento tipo, incluindo a montagem da fôrma, concretagem e desfôrma (Quadro 2), e a criação da simulação 4D do processo (Figuras 13 e 14).

\section{Figura 9 - Quantificação extraída da modelagem}

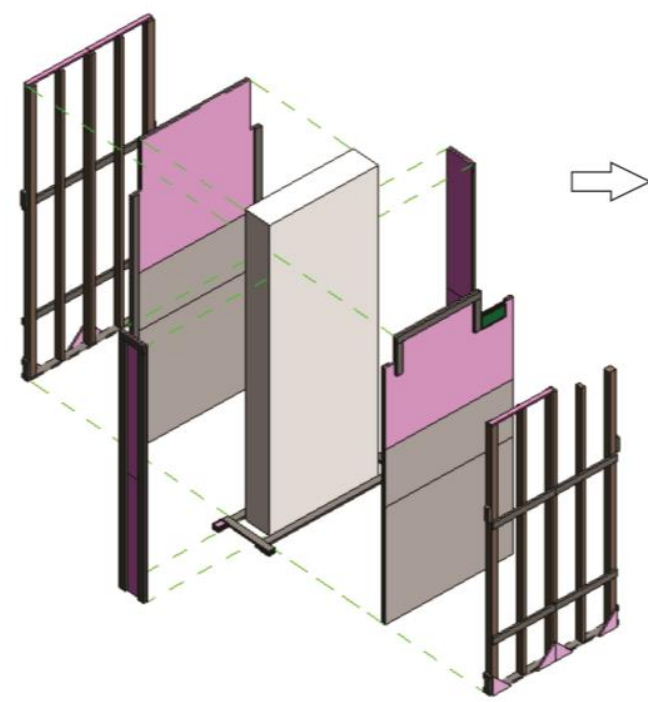

\begin{tabular}{|l|c|l|}
\hline \multicolumn{3}{|c|}{ ¿Compensado para pilar e vigas } \\
\hline A & B & \multicolumn{1}{|c|}{ C } \\
\hline Pesa & Area & Numero de chap \\
\hline & & \\
\hline & $236.546 \mathrm{~m}^{2}$ & 88 \\
\hline Compensado cortado & $610,746 \mathrm{~m}^{2}$ & 102 \\
\hline Compensado deitado & $218,965 \mathrm{~m}^{2}$ & 65 \\
\hline Compensado en pé & $866,235 \mathrm{~m}^{2}$ & 235 \\
\hline
\end{tabular}

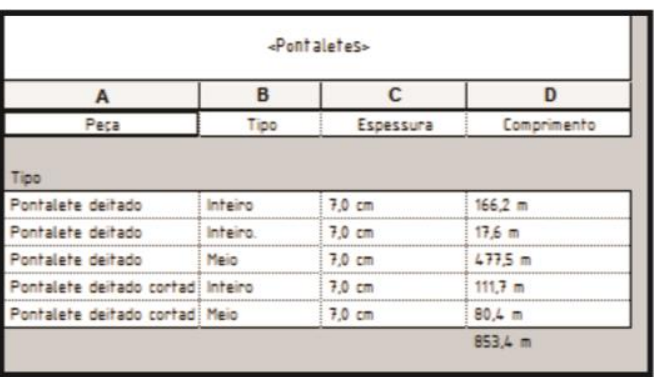

\begin{tabular}{|c|c|c|c|c|}
\hline \multicolumn{5}{|c|}{ Sarrafos= } \\
\hline A & B & C & D & $E$ \\
\hline Pesa & Largura & Espessura & Comprimento & Pesa de origen \\
\hline \multicolumn{5}{|l|}{ Tipo } \\
\hline Sarrafo detado & $7.0 \mathrm{~cm}$ & $2.2 \mathrm{~cm}$ & $126.9 \mathrm{~m}$ & Gastalinos \\
\hline Sarrafo virado & $5,0 \mathrm{~cm}$ & $3.5 \mathrm{~cm}$ & $15,6 \mathrm{~m}$ & Grade de plar \\
\hline Sarrafo deitado & $7.0 \mathrm{~cm}$ & $2.2 \mathrm{~cm}$ & $155,3 \mathrm{~m}$ & Grade de plar \\
\hline Sarrafo virado & $7.0 \mathrm{~cm}$ & $2.2 \mathrm{~cm}$ & $98.5 \mathrm{~m}$ & Grade de plar \\
\hline Sarrafo deitado & $7,0 \mathrm{~cm}$ & $2.2 \mathrm{~cm}$ & $705,2 \mathrm{~m}$ & Painel de plar \\
\hline Sarrafo de topo & $7,0 \mathrm{~cm}$ & $2.2 \mathrm{~cm}$ & $52.1 \mathrm{~m}$ & Painel de viga \\
\hline Sarrafo deitado & $7.0 \mathrm{~cm}$ & $2,2 \mathrm{~cm}$ & $595,3 \mathrm{~m}$ & Painel de viga \\
\hline
\end{tabular}

Fonte: Neiva Neto (2014). 
Figura 10 - Sequência de instanciação da fôrma de pilar: (1) gastalhos; (2) painéis frontais; (3) painéis laterais; e (4) grade

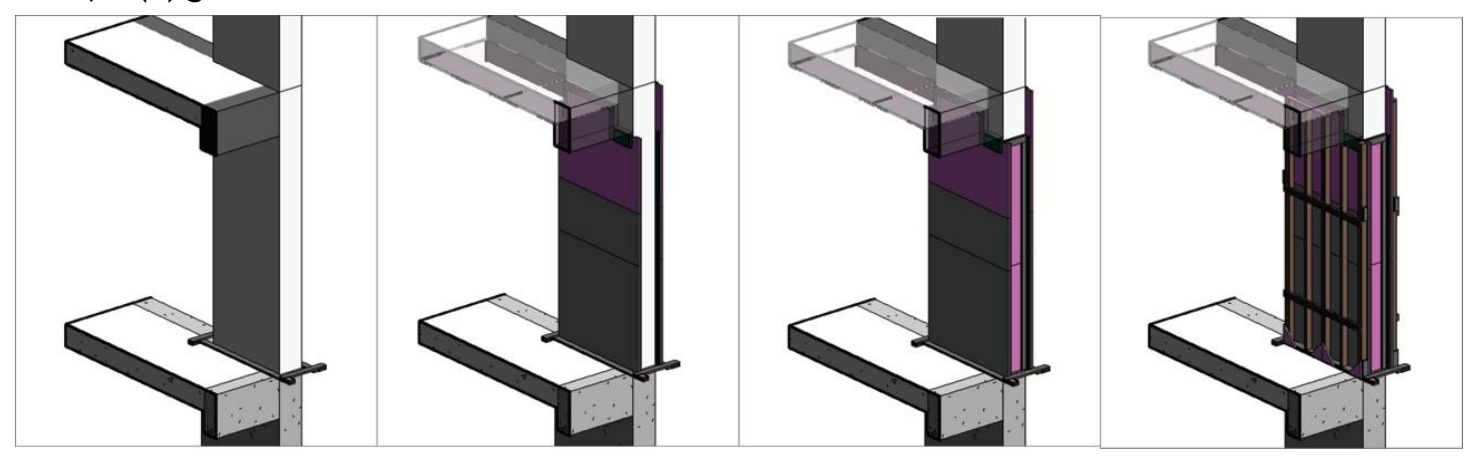

Fonte: Neiva Neto (2014).

Figura 11 - Sequência de instanciação da fôrma de viga: (1) fundo de viga; (2) painéis laterais; e (3) escoramento
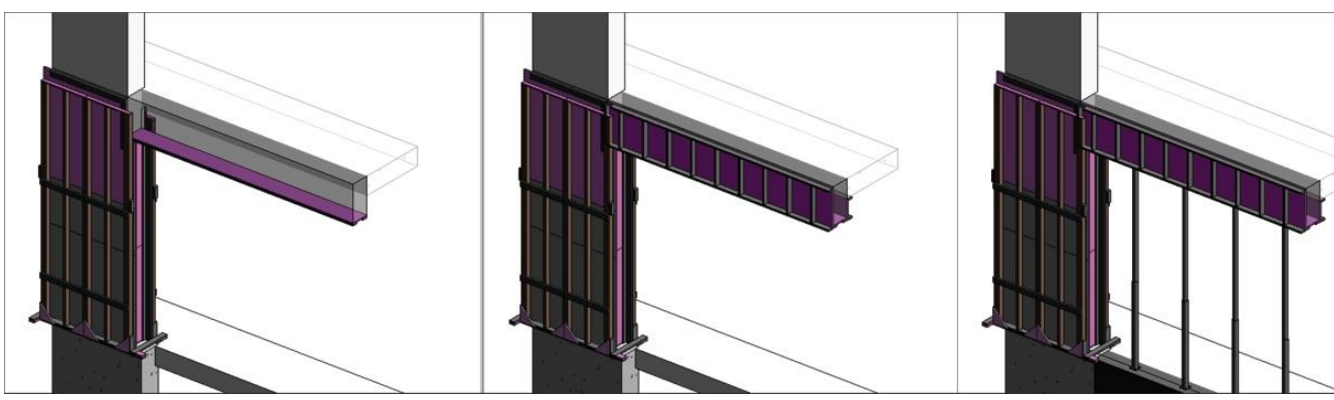

Fonte: Neiva Neto (2014)

Figura 12 - Sequência de instanciação da fôrma de laje: (1) painéis de laje; e (2) escoramento da laje
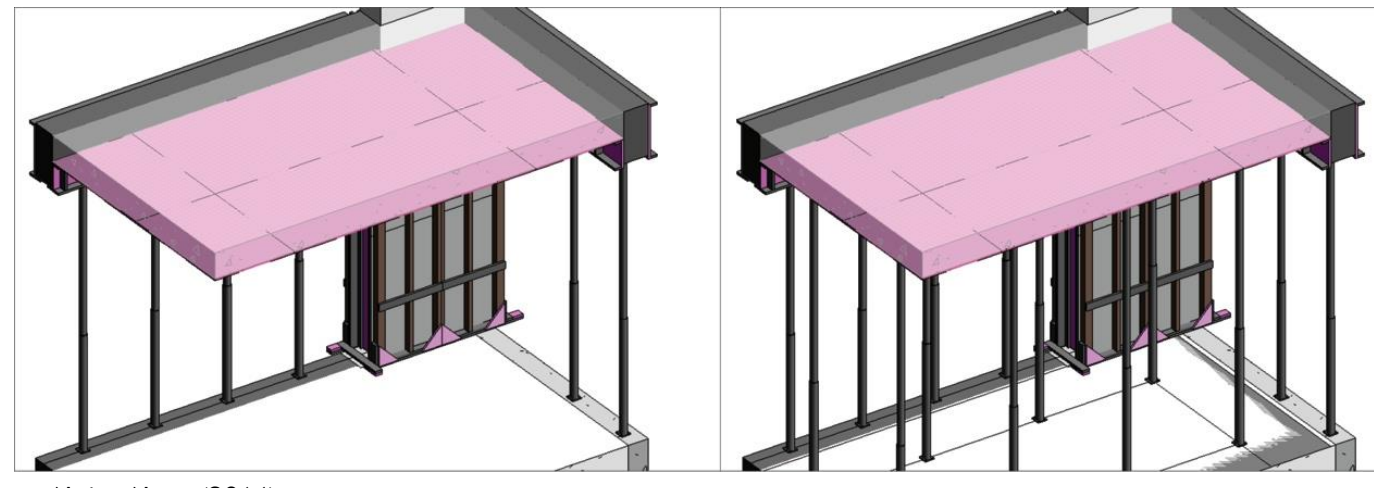

Fonte: Neiva Neto (2014).

Quadro 2 - Cronograma do ciclo de concretagem

\begin{tabular}{|l|l|l|l|l|l|l|l|l|l|l|}
\hline \multicolumn{1}{|c|}{ Tarefa } & S & T & Q & Q & S & S & D & S & T & Q \\
\hline Montagem de gastalhos & & & & & & & & & & \\
\hline Colocação dos painéis laterais dos pilares em forma de U & & & & & & & & & & \\
\hline Colocação da armação dos pilares & & & & & & & & & & \\
\hline Fechamento dos painéis dos pilares & & & & & & & & & & \\
\hline Estruturação das fôrmas de pilar & & & & & & & & & & \\
\hline Colocação de fundos de viga e painéis laterais de viga & & & & & & & & & & \\
\hline Montagem do forro de laje & & & & & & & & & & \\
\hline Montagem da armação da laje & & & & & & & & & \\
\hline Concretagem & & & & & & & & & & \\
\hline
\end{tabular}

Fonte: Neiva Neto (2014). 
Figura 13 - Simulação da montagem das fôrmas de pilar

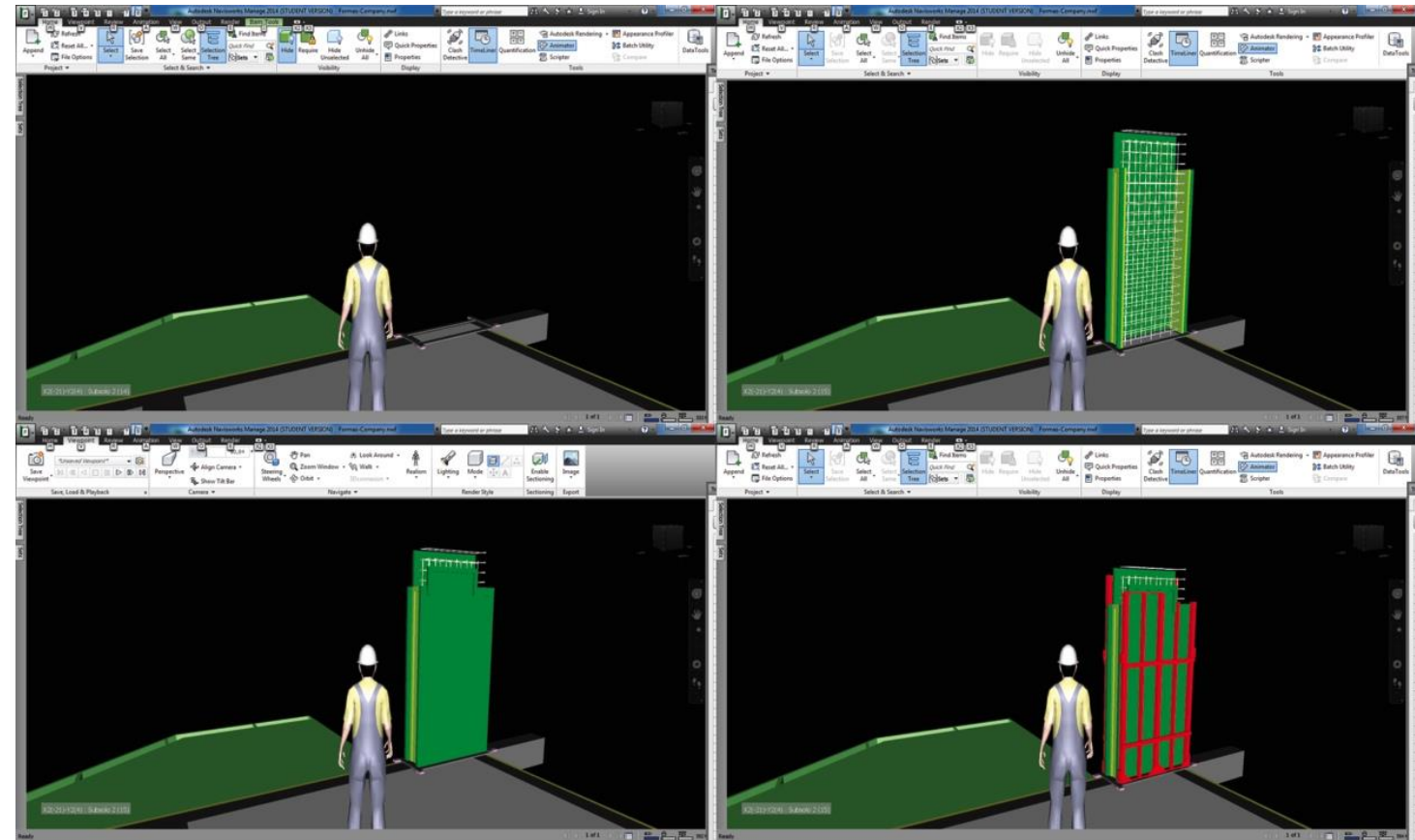

Fonte: Neiva Neto (2014).

Figura 14 - Visualização da etapa construtiva

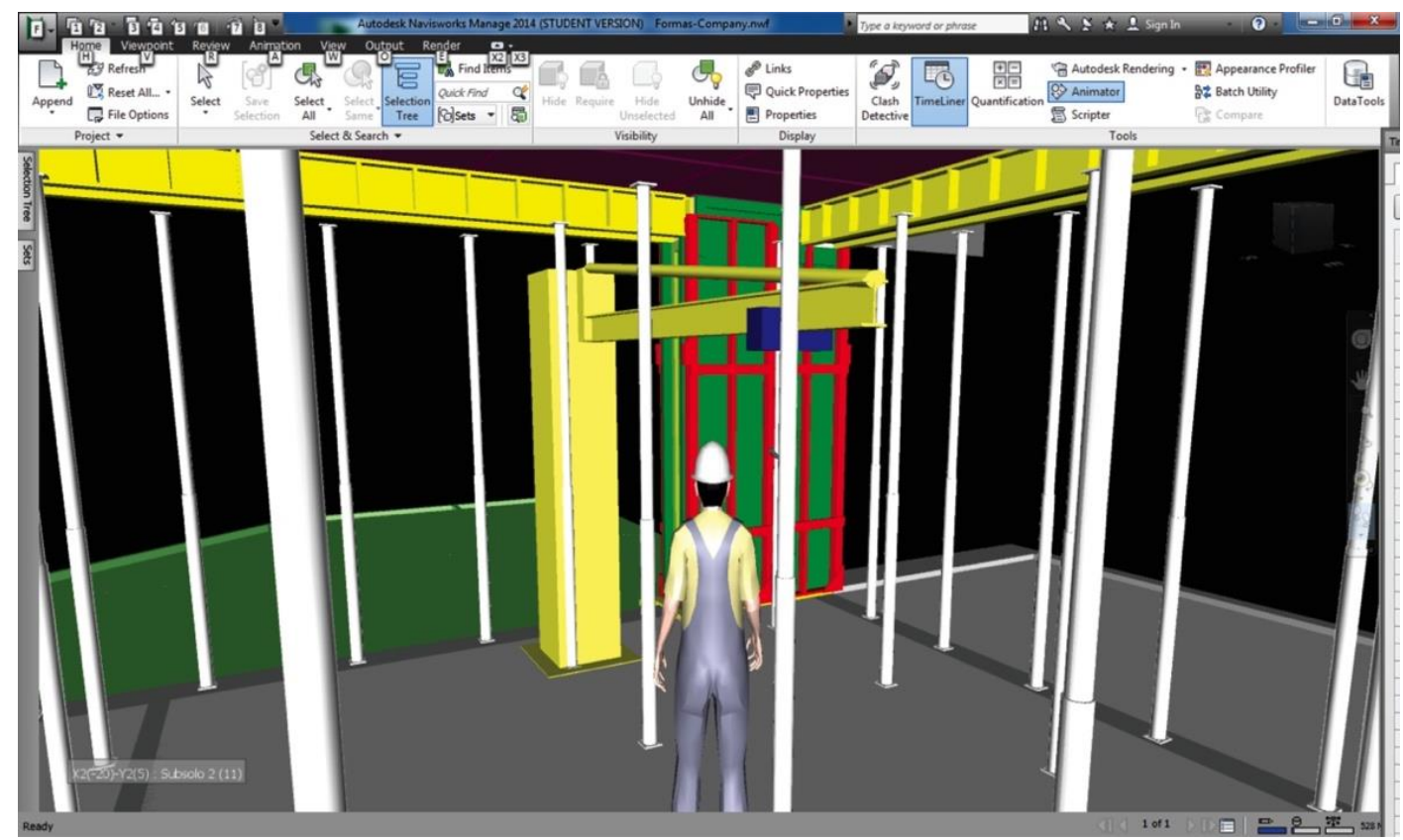

Fonte: Neiva Neto (2014).

Visando identificar o nível de dificuldade de entendimento e da trabalhabilidade dos componentes no ambiente do Revit e do Navisworks, ao final do exercício aplicou-se um questionário sobre o processo aos 24 alunos que participavam da disciplina. Os alunos não consideraram o processo de instanciação das fôrmas no Revit Structure difícil, mas sim compreensível; porém demandando prática (Figura 15). Observou-se grande potencial de aceitação da biblioteca de componentes de fôrma entre os alunos, que a consideraram muito úteis ou úteis, principalmente para o apoio à visualização em projeto (Figura 16).

196 Neiva Neto, R. da S.; Ruschel, R. C. 
Quanto ao nível de dificuldade da inclusão das fôrmas envolvendo a estrutura de concreto percebe-se que os alunos consideraram a tarefa de regular a muito difícil de ser executada, sendo a fôrma de pilar mais difícil de inserir, seguida pela fôrma de viga e pela fôrma de laje (Figura 17).

Uma grande dificuldade encontrada neste exercício foi a associação dos elementos de fôrma às atividades do cronograma no aplicativo Navisworks. Isso se deu pela não associação dos componentes de fôrma - pilar, viga e laje - aos pisos da edificação. Portanto, ao final desse exercício foi necessário retomar etapas do desenvolvimento da biblioteca e reformulá-las para que pudessem alcançar melhores níveis de trabalhabilidade. Essa questão foi resolvida através da inserção de um parâmetro compartilhado ID de tarefa nas famílias aninhadas, possibilitando o rastreamento da informação dos componentes após sua importação para um aplicativo de gerenciamento de modelos, como o Navisworks.

Finalizadas todas as etapas anteriores da pesquisa, aplicou-se a solução proposta para o desenvolvimento de um projeto de fôrmas de um empreendimento comercial localizado em Aparecida de Goiânia, no Estado de Goiás, com um total de $25.000 \mathrm{~m}^{2}$, sendo duas torres de 20 pavimentos (Figura 18). Esse projeto demandou aproximadamente 20 dias trabalhados com o auxílio de um estagiário estudante de Engenharia Civil do $5^{0}$ ano de graduação. Toda a documentação foi enviada para a obra e possibilitou a confecção do sistema de fôrmas de forma planejada e sistematizada, que é o intuito dos projetos construtivos. Foi esse processo de validação que apontou a necessidade de criar Assemblies para se extrair a documentação do projeto de fôrmas de forma mais ágil (Figura 7).

\section{Figura 15 - Compreensão do modelo estrutural na ferramenta Revit STRUCTURE}

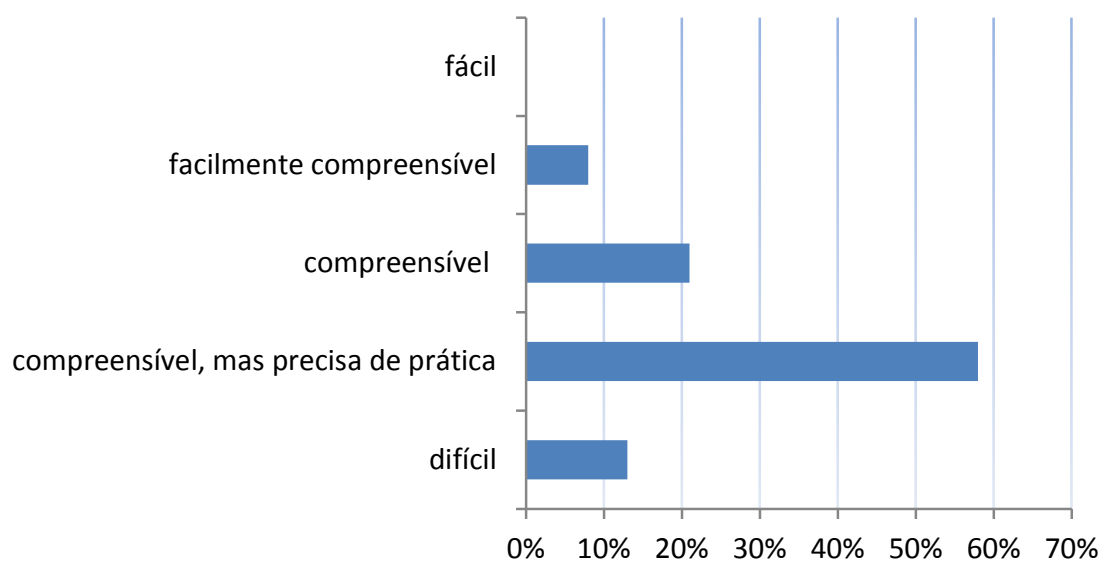

Fonte: Neiva Neto (2014).

Figura 16 - Opinião sobre a utilidade da biblioteca de fôrma de concreto armado

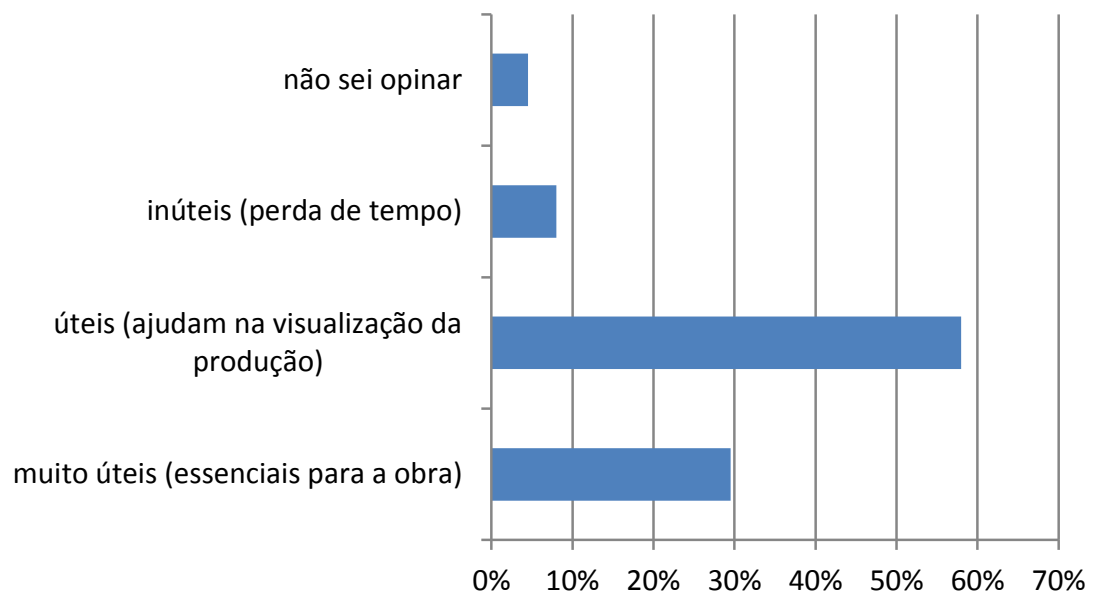

Fonte: Neiva Neto (2014). 
Figura 17 - Nível de dificuldade declarado da modelagem dos componentes do projeto de fôrmas

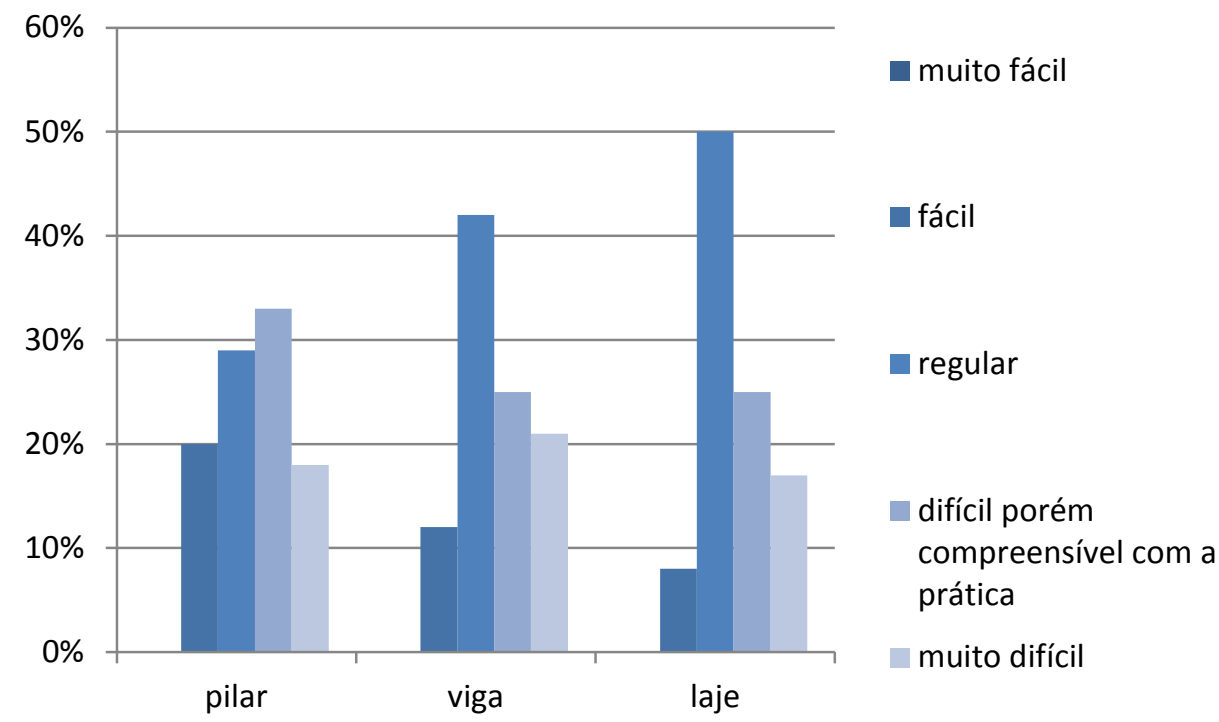

Fonte: Neiva Neto (2014).

Figura 18 - Fôrmas de pilar e de lajes executadas
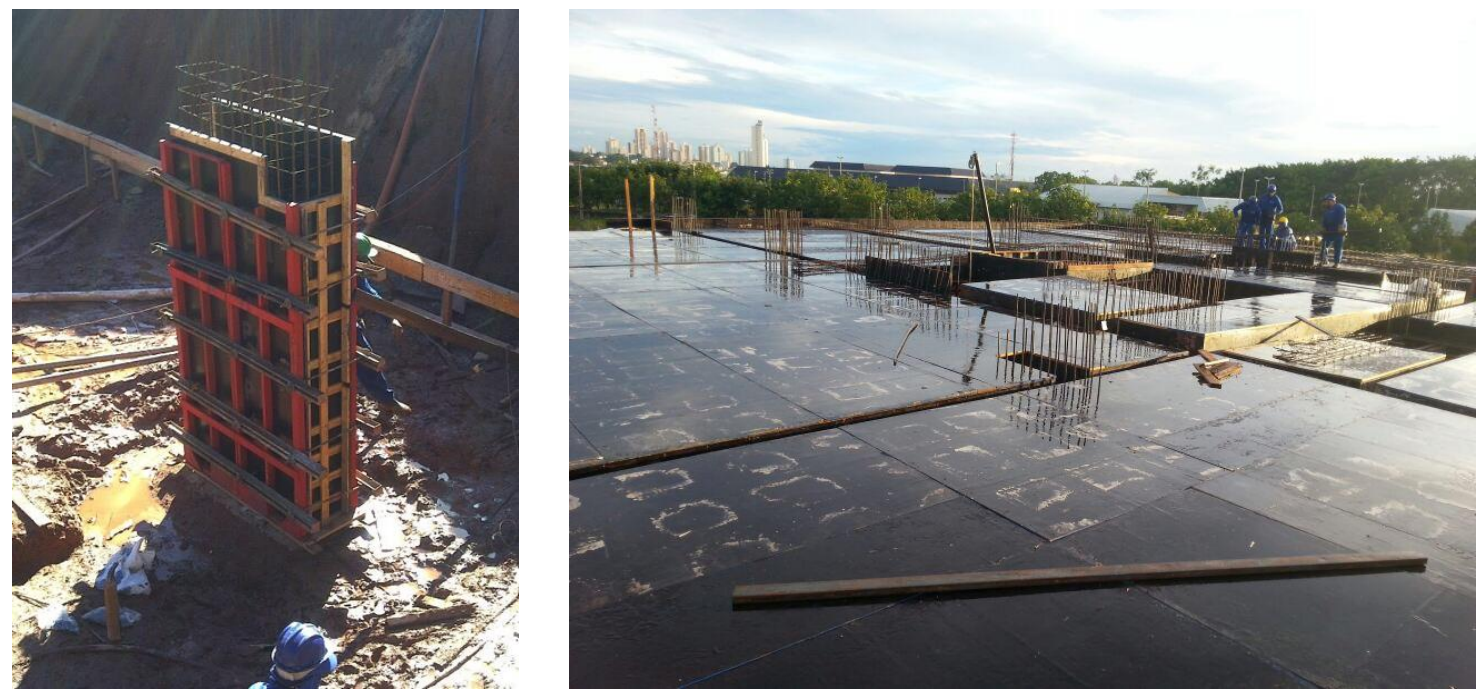

Fonte: Neiva Neto (2014).

Também, nesta aplicação em projeto real da solução em BIM para o PCFM foi possível avaliar o suporte dela para análise de custo. A análise de custo de uma obra é feita por orçamentistas que preveem a quantidade de material e mão de obra a serem gastos por uma unidade de medida (metro quadrado, metro linear, metro cúbico, etc.) de determinado serviço de obra. Essas informações são dispostas em tabelas que são denominadas de composições de serviço. No caso das fôrmas de madeira, a composição de serviço possui a quantidade de material e mão de obra para a execução de um metro quadrado de fôrma de madeira de determinado subsistema (pilar, viga e laje). Na Tabela 1 tem-se um exemplo de composição de serviço para a orçamentação do serviço de confecção de fôrmas de pilar a ser moldado e desmoldado no máximo 12 vezes, ou seja, para um edifício de 12 pavimentos. O preço por metro quadrado da composição é multiplicado pela metragem quadrada, que representa a área total de contato do molde da fôrma com o concreto. Ao final, tem-se o valor total a ser gasto para a confecção de todas as fôrmas de pilar da obra. Dessa forma, fazendo uso de outras composições para as fôrmas de viga e laje, obtémse ao final o custo total do sistema de fôrmas.

198 Neiva Neto, R. da S.; Ruschel, R. C. 
Tabela 1 - Composição de serviço de fôrmas

\begin{tabular}{|c|c|c|}
\hline \multicolumn{3}{|c|}{$\begin{array}{c}\text { Fôrma feita em obra para Pilares, com chapa } \\
\text { compensada plastificada, } \mathrm{e}=12 \mathrm{~mm} \\
(12 \text { aproveitamentos })-\text { unidade: } \mathbf{~ m}^{2}\end{array}$} \\
\hline Material & un. & coeficiente \\
\hline Sarrafo de $2,2 \times 7 \mathrm{~cm}$ & $\mathrm{~m}$ & 0,681 \\
\hline Painel de compensado de $12 \mathrm{~mm}$ & $\mathrm{~m}^{2}$ & 0,112 \\
\hline Pontalete de $7 \times 7 \mathrm{~cm}$ & $\mathrm{~m}$ & 0,515 \\
\hline Prego 17x21 com cabeça & $\mathrm{kg}$ & 0,017 \\
\hline Prego $17 \times 27$ com cabeça dupla & $\mathrm{kg}$ & 0,20 \\
\hline $\begin{array}{l}\text { Desmoldante de fôrmas para } \\
\text { concreto }\end{array}$ & $\mathrm{L}$ & 0,02 \\
\hline Arame galvanizado 12 & $\mathrm{~kg}$ & 0,18 \\
\hline \multicolumn{3}{|l|}{ Mão de obra } \\
\hline Carpinteiro & $\mathrm{h}$ & 0,66 \\
\hline Ajudante de carpinteiro & $\mathrm{h}$ & 0,165 \\
\hline
\end{tabular}

Fonte: Pini (2013).

\section{Contribuição}

Foi desenvolvida uma biblioteca de componentes, na plataforma BIM Revit Structure, para o projeto de fôrmas de madeira, permitindo usos de BIM tais como modelagem paramétrica para suporte a autoria de soluções, de quantificação e orçamentação para estimativa de custo; de compatibilização 3D para a coordenação de projeto; de prototipagem virtual para documentação e visualização do modelo; e de simulação 4D para o planejamento da obra. A proposta foi validada em ambiente de ensino, na prática de projeto e na execução da obra, demonstrando a capacidade de alcance dela. A automação da documentação e da quantificação se alinha com demandas do mercado da construção civil brasileira. Outro aspecto diz respeito a como a proposta pode ilustrar processos construtivos. Nesse sentido, a simulação 4D potencializa a visualização do sistema construtivo de fôrmas, possibilitando avaliações de construtibilidade, além de melhorar a comunicação do projeto.

Verificou-se que a pesquisa é consonante com os poucos estudos internacionais pioneiros $\mathrm{e}$ semelhantes, sendo contextualizada para o cenário nacional. Identificou-se também que todas as pesquisas que tratam de BIM associado a fôrmas requerem um modelo de informação que inclua a modelagem de fôrmas nele. Dessa forma, esta proposta é também fundamental, pois viabiliza desdobramentos e ajuda ampliar a incorporação de BIM na cadeia produtiva da construção civil. Nesse âmbito, o desenvolvimento do PCFM em BIM demonstrado é passível de ser replicado para outros sistemas de fôrmas, permitindo um refinamento de um processo anteriormente desenvolvido em CAD.
Em se tratando das contribuições específicas da pesquisa, aponta-se para a proposição de um método para desenvolvimento de bibliotecas cíclico considerando variados usos de BIM. Este método demonstrou ser essencial para o desenvolvimento de bibliotecas robustas de componentes BIM viáveis de utilização por diferentes intervenientes em todo o ciclo da construção.

\section{Referências}

ALWISY, A.; AL-HUSSEIN, M.; AL-JIBOURI, S. H. BIM Approach for Automated Drafting and Design for Modular Construction Manufacturing. In: INTERNATIONAL CONFERENCE IN COMPUTING IN CIVIL ENGINEERING, 2012, Clearwater. Proceeding... Reston: American Society of Civil Engineers, 2012.

\section{AUTODESK. Autodesk Revit 2015 Help.}

Disponível em:

<http://help.autodesk.com/view/RVT/2015/ENU/? guid=GUID-4EBB97AD-C7B6-4828-91EBBC0E99B81E43 >. Acesso em: 7 ago. 2015.

BARROS, M. M. S. B. de; MELHADO, S. B. Recomendações Para a Produção de Estruturas de Concreto Armado em Edifícios. 2006. Notas de Aula. São Paulo: Escola Politécnica da Universidade de São Paulo.

BIOTTO, C. N.; FORMOSO, C. T.; ISATTO, E. L. Uso de Modelagem 4D e Building Information Modeling na Gestão de Sistemas de Produção em Empreendimentos de Construção. Ambiente Construído, Porto Alegre,v. 15, n. 2, p. 65-77, abr./jun. 2015. 
BOEHMIG, R. L. Shop Drawings: in need of respect. Civil Engineering, Reston, v. 60, n. 3, p; 80-82, mar. 1990.

CÂMARA BRASILEIRA DA INDÚSTRIA DA CONSTRUÇÃO; FUNDAÇÃO GETÚLIO VARGAS. A Produtividade da Construção Civil Brasileira. Ago 2012. Disponível em: $<$ http://www.cbicdados.com.br/media/anexos/068. pdf $>$. Acesso em: 20 jul. 2015.

CHI, S.; HAMPSON, K.; BIGGS, H. Using BIM for Smarter and Safer Scaffolding and Formwork Construction : A Preliminary. In: CIB W099 INTERNATIONAL CONFERENCE ON MODELING AND BUILDING HEALTH AND SAFETY, Singapore, 2012. Proceeding... Singapore: CIB, 2012.

\section{COMPUTER INTEGRATED CONSTRUCTION} RESEARCH PROGRAM. BIM Project

Execution Planning Guide. Version 2.1. The Pennsylvania State University, University Park, PA, USA, May 2011. Disponível em <http://bim.psu.edu/default.aspx >. Acesso em: 21 jul. 2014.

\section{EASTMAN, C. et al. Manual de BIM}

Handbook: um guia de modelagem da informação da construção para arquitetos, engenheiros, gerentes, construtores e incorporadores. Tradução de Cervantes Gonçalve Ayres Filho et al. Porto Alegre: Bookman, 2014.

GELISEN, G. Automated Productivity-Based Schedule Animation: Simulation-Based Approach to Time-Cost Trade-Off Analysis. Journal of Constructtion Engeneering and Management, Reston, v. 140, n. 4, p. B4013007, abr. 2014.

GOLPARVAR-FARD, M.; SAVARESE, S.; PEÑA-MORA, F. Automated Model-Based Recognition of Progress Using Daily Construction Photographs and IFC-Based 4D Models. In: CONSTRUCTION RESEARCH CONGRESS, Banff, 2010. Proceedings... Reston: American Society of Civil Engineers, 2010.

IRIZARRY, J.; AKNOUKH, A.; MEADATI, P. BIM and Concrete Formwork Repository. In: ASC ANNUAL INTERNATIONAL CONFERENCE PROCEEDINGS, 47., Omaha, 2011.

Proceeding... 2011. Omaha: ASC, abr. 2011.

JIANG, L.; LEICHT, R. Automated Rule-Based Constructability Checking: Case Study of Formwork. Journal of Management in Engineering, Reston, v. 31, n.1., p. A4014004, jan. 2015.
JIANG, L.; LEICHT, R. M.; KREMER, G. E. O. Eliciting Constructability Knowledge for BIMenabled Automated, Rule-based Constructability Review: A Case Study of Formwork. In: CONSTRUCTION RESEARCH CONGRESS, Atlanta, 2014. Proceeding... Reston: American Society of Civil Engineers, mai. 2014.

KANG, J.; GANAPATHI, J. L.; FAGHIHI, V. BIM to field: robotic total station and BIM for quality control. In: GUDNASON, G.; SCHERER, R. (Eds.). eWork and eBusiness in Architecture, Engineering and Construction. London: Taylor \& Francis Group, 2012.

KANNAN, R. M.; SANTHI, H. M.

Constructability Assessment of Climbing Formwork Systems Using Building Information Modeling. Procedia Engineering, v. 64, p. 11291138, 2013.

LEE, C.; HAM, S.; LEE, G. The Development of Automatic Module For Formwork Layout Using BIM. System, v. 7, n. 3, p.1-6, mai. 2009.

LUKKA, K. The Constructive Research Approach. In: OJAL, L.; HILMOLA, O-P. (Eds.). Case Study Research in Logistics. Publications of the Turku School of Economics and Business Administration, 2003. Series B1.

LUTH, G. P.; SCHORER, A.; TURKAN, Y. Lessons From Using BIM to Increase DesignConstruction Integration. Practice Periodical on Structural Design and Construction, Reston, v. 19, n. 1, p. 103-110, fev. 2014.

MELHADO, S. B. (Coord.) Coordenação de Projetos de Edificações. São Paulo: O Nome da Rosa, 2005.

MELHADO, S. B.; FABRÍCIO, M. M. Projetos da Produção e Projetos Para Produção na Construção de Edifícios: discussão e síntese de conceitos. In: ENCONTRO NACIONAL DO AMBIENTE CONSTRUÍDO, 7., Florianópolis, 1998. Anais... Florianópolis: UFSC, 1998.

NEIVA NETO, R. da S. O Projeto da Produção de Formas de Estrutura de Concreto Armado Incorporando BIM. Campinas, 2014. $133 \mathrm{f}$. Dissertação (Mestrado em Engenharia Civil) Faculdade de Engenharia Civil, Arquitetura e Urbanismo, Universidade Estadual de Campinas, Campinas, 2014.

PIETROFORTE, R. Shop Drawing Process of Stone Veneered C ladding systems. Journal of Architectural Engineering, v. 3, n. 2, p. 70-79, 1997.

PINI. TCPO - Tabela de Composição de Preços para Orçamento. São Paulo: PINI, 2013. 
SABBATINI, F. H.; AGOPYAN, V. Desenvolvimento de Métodos, Processos e Sistemas Construtivos. São Paulo: Escola Politécnica da Universidade de São Paulo, 1991.

\section{SILVA, M. M. de A. Diretrizes Para o Projeto} de Alvenarias de Vedação. São Paulo, 2003. Dissertação (Mestrado em Engenharia Civil) Escola Politécnica, Universidade de São Paulo, São Paulo, 2003.

TURKAN, Y. et al. Tracking Secondary and Temporary Concrete Construction Objects Using 3D Imaging Technologies. In: ASCE INTERNATIONAL WORKSHOP ON COMPUTING IN CIVIL ENGINEERING, Los Angeles, 2013. Proceeding... Reston: American Society of Civil Engineers, 2013.
WANG, W.-C. et al. Integrating Building Information Models With Construction Process Simulations For Project Scheduling Support. Automation in Construction, v. 37, p. 68-80, jan. 2014.

WILLIAMS, N. et al. A Case Study of a Collaborative Digital Workflow in the Design and Production of Formwork for " Non- Standard" Concrete Structures . a case study of a collaborative digital workflow in the design and production of formwork. International Journal of Architecture Computing, v. 9, n. 3, p. 223-240, 2011.

Romeu da Silva Neiva Neto

Innovar Construtora | Av. T-1, 2203, Setor Bueno | Goiânia - GO - Brasil | CEP 74210-025 | Tel.: (62) 4006-2600 Ramal 2637 | E-mail: romeuneiva@gmail.com

\section{Regina Coeli Ruschel}

Departamento de Arquitetura e Construção, Faculdade de Engenharia Civil, Arquitetura e Urbanismo | Universidade Estadual de Campinas

Av. Albert Einstein, 951, Cidade Universitária | Caixa Postal 6021 | Campinas - SP - Brasil | CEP 13083-852 | Tel.: (19) 3521-2051 | E-mail: regina.ruschel@gmail.com

\section{Revista Ambiente Construído}

Associação Nacional de Tecnologia do Ambiente Construído

Av. Osvaldo Aranha, $99-3^{\circ}$ andar, Centro

Porto Alegre - RS - Brasil

CEP $90035-190$

Telefone: +55 (51) 3308-4084

Fax: +55 (51) 3308-4054

www.seer.ufrgs.br/ambienteconstruido

E-mail: ambienteconstruido@ufrgs.br 